1090 Vienna, Austria. E-mail: sci-genpsy@ meduniwien.ac.at

D. J. Stein University of Stellenbosch, Cape Town, South Africa and University of Florida, Gainesville, Florida, USA

H. Loft H. Lundbeck A/S, Copenhagen, Denmark

R. Nil Lundbeck (Switzerland) Ltd, Glattbrugg, Switzerland

\section{Choosing psychiatry as a career}

As a graduate of 2000 and a participant in Goldacre et al's survey, I was keen to reflect on which influences led me towards psychiatry and how these compared with those of others. Interestingly, the paper reports that only a small percentage of those entering the specialty had intentions to do so before medical school $(18 \%)$. Thus major influences on career choice are the curriculum, clinical experience and inspiring teachers. My own experience would be consistent with this, along with an interest held by my peer group at medical school. As an Edinburgh graduate I was interested to find that Edinburgh had the highest percentage of doctors choosing psychiatry, after 3 years, of all UK medical schools. Edinburgh has a notable academic department through which the curriculum is conducted but other medical schools with large academic units do not appear to attract as many candidates into the discipline. If recruitment into psychiatry became a problem, at what point should the curriculum at medical schools be reassessed at a national level or by the Royal College of Psychiatrists? Surely the future of psychiatry is dependent on the engaging of prospective students with the corpus of academic and clinical excellence.

Goldacre, M. J., Turner, G., Fazel, S., et al (2005) Career choices for psychiatry: national surveys of graduates of 1974-2000 from UK medical schools. British Journal of Psychiatry, 186, I58-164.

B. J. Baig Department of Psychiatry, Royal Edinburgh Hospital, Morningside Park, Edinburgh EI0 5HF, UK. E-mail: benbaig@doctors.org.uk

\title{
One hundred years ago
}

\section{Family care of the insane}

IN drawing attention last March to the conclusions favourable to the family care of the insane which could fairly be arrived at from the reports of our Special Commissioner on the Care of the Insane Poor, we promised to return to the subject when our Commissioner should have had an opportunity of supplementing his report on the progress achieved on the Continent and in Scotland, and should have given an account of the boarding out of the insane as it is practically carried out in England.

We accordingly invite the careful perusal of the report appearing in this number of the BRITISH MEDICAL JOURNAL by our Commissioner on the Family Care of the Insane Poor in England and Wales. From beginning to end this document furnishes a very remarkable contrast to the earlier reports. In every country where family care has been carried out with an intelligent desire to improve the condition of the insane, the method has found warm advocates, and even where there has not been unanimity of approval in detail, family care is proudly pointed to as the most advanced and most beneficent mode of dealing with a great number of the most afflicted class of the population. But in England so little is known of the matter, and so little public interest has been excited in the topic, that many persons were probably unaware of the existence of an English form of family care. It would most likely be hardly justifiable to say that the procedure is carried out in a surreptitious manner, but certainly it is seldom spoken of. Nobody appears to be proud of it, and those who read our Commissioner's reports will not wonder at this. The system of dealing with these 5,000 and more unfortunate persons of unsound mind is not altogether creditable to a country which, in the early days of non-restraint, was proud to consider itself in the van of progress with regard to the treatment and care of the insane. This is the more remarkable seeing how much attention has been paid to the perfection of the family-care system in almost every other country in Europe.

The condition of the victims of this system is much the same practically as that of all the insane before there were any lunacy laws whatever. These patients are, as our Commissioner justly observes, detached from the general lunacy administration of the country. They are regarded merely as paupers, and are only supervised in so far as they are dependent upon the rates. The public appears to forget that these poor people are sufferers from a condition which renders them particularly dependent. It is notorious that custodians of the insane are particularly liable to the temptations of cupidity and of cruelty, leading, unless there be careful supervision, to the probability of ill-usage and almost the certainty of neglect. The elaborate precautions which the law has gradually made more stringent for the protection of the insane in asylums are well known. Here in great institutions, running like clockwork, where hundreds of eyes are upon everybody, the law provides the most elaborate machinery to prevent abuses. In ludicrous contrast to this is the official neglect of the wretched pauper imbecile, who, being unable from his poverty, friendlessness, and dementia, to make efficient representations for himself, should be the special object of care. At the bottom of all this absurdity and inconsistency is the perverse view of insanity which the English law has made familiar. The law is unwilling to recognize anything as insanity which does not involve danger to the person or the pockets of the lieges. Even where there is personal danger, however, that great nightmare "the liberty of the subject" is always ready to gallop across the scene. Society scarcely recognizes that it owes any duty to the insane who are not dangerous and are not in asylums. The duty of curing the victims of a pitiable disease or of securing kindly and sufficient care for those whose infirmity has obviously made them subjects for public protection, would seem to be insufficiently understood. 